\title{
Human diploid fibroblast growth on polystyrene microcarriers in aggregates
}

\author{
James Varani ${ }^{1}$, Sean Josephs ${ }^{1,2}$ \& William J. Hillegas ${ }^{2}$ \\ ${ }^{1}$ The Department of Pathology, The University of Michigan, Ann Arbor, Michigan, USA; ${ }^{2}$ SoloHill Laboratories, \\ Ann Arbor, Michigan, USA
}

Key words: aggregation, bioreactor, cell growth, diploid fibroblasts, microcarriers, suspension

\begin{abstract}
Polystyrene microcarriers were prepared in four size ranges (53-63 $\mu \mathrm{m}, 90-125 \mu \mathrm{m}, 150-180 \mu \mathrm{m}$ and 300-355 $\mu \mathrm{m})$ and examined for ability to support attachment and growth of human diploid fibroblasts. Cells attached rapidly to the microcarriers and there was a direct relationship between cell attachment and microcarrier aggregation. Phasecontrast and scanning electron microscopic studies revealed that while aggregation was extensive, most of the aggregate consisted of void volume. Cell growth studies demonstrated that human diploid fibroblasts proliferated well in microcarrier aggregates, reaching densities of $2.5-3 \times 10^{6}$ cells per $2 \mathrm{ml}$ dish after 6 days from an inoculum of $0.5 \times 10^{6}$ cells per dish. When cells were added to the microcarriers at higher density (up to $5 \times 10^{6}$ cells per 2 -ml culture), there was little net growth but the cells remained viable over a 7-day period. In contrast, cells died when plated under the same conditions in monolayer culture. When the microcarriers were used in suspension culture, rapid cell attachment and rapid microcarrier aggregation also occurred. In 100-ml suspension culture, a cell density of $0.7 \times 10^{6}$ cells per ml was reached after 7 days from an inoculum of $0.1 \times 10^{6}$ cells. Based on these data, we conclude that microcarrier aggregation is not detrimental to fibroblast growth. These data also indicate that small microcarriers (53-63 $\mu \mathrm{m}$ ) (previously thought to be too small to support the growth of diploid fibroblasts) can support fibroblast growth and this occurs primarily because microcarriers in this size range efficiently form aggregates with the cells.
\end{abstract}

\section{Introduction}

In vitro cultivation of anchorage-dependent cells has traditionally been done using culture formats (i.e., flatbottom flasks and roller bottles) that allow the cells to grow as a monolayer. When microcarriers were first introduced (Van Wezel, 1967; Nielson \& Johannson, 1980) use-protocols were designed to minimize microcarrier aggregation. This allowed for cell growth in bioreactors while maintaining the essential characteristics of monolayer culture. The first studies to contradict the widely-held impression that microcarrier aggregation would be detrimental were carried out by Goetghebeuer and $\mathrm{Hu}$ (1991). They showed that small DEAE-dextram beads (prepared by coupling DEAE to Sephadex G25-G50) could be used to successfully grow three different established cell lines (Vero, Chi- nese hamster ovary and swine testes). With the small microcarriers, aggregates formed, leading to cell yields of $2-3 \times 10^{6}$ cells per $\mathrm{ml}$. Cell yields were $50-100 \%$ higher than on large beads of the same composition. Subsequent studies by Alves et al. (1994) demonstrated similar behavior with baby hamster kidney cells. Together, these studies provided initial information to indicate that some types of cells could be grown in microcarrier aggregates, resulting in high cell yields. It might be argued that established cell lines are the least likely to be affected by growth in aggregates. Indeed, chinese hamster ovary cells can be adapted to grow in suspension without any substrate. However, recent studies by Lewis et al. (1994) suggest that this is not the case. These investigators found that chick embryo fibroblasts were also capable of growing to high density in microcarrier aggregates. Thus, survival of cells in 
aggregates is not unique to transformed cell lines. The present studies extend these earlier observations. In the studies described here, we have prepared polystyrene microcarriers in various size ranges. The microcarriers were examined for ability to support attachment and growth of human diploid fibroblasts. Attachment and growth data were correlated with microcarrier aggregation.

\section{Materials and methods}

Cells. Human neonatal (foreskin) fibroblasts were used in the present studies. They were isolated as described previously (Phan et al., 1985) and grown in plastic flasks. Culture medium consisted of Dulbecco's modified minimal essential medium of Eagle with Earle's salts, non-essential amino acids, antibiotics and $10 \%$ fetal bovine serum (DMEM-FBS). The medium was from GIBCO (Grand Island, NY) and the serum was from Hyclone Laboratories (Logan, UT). Growth was at $37^{\circ} \mathrm{C}$ in an atmosphere of $5 \% \mathrm{CO}_{2} / 95 \%$ ) air. Cells were used through the fifth passage and subcultured by exposure to trypsin/EDTA as required.

Substrates. The substrates for cell growth consisted of polystyrene microcarriers manufactured by SoloHill Labs (Ann Arbor, MI). The microcarriers were prepared as a single lot of polystyrene beads and then separated by sieving into the desired size ranges. Size ranges included 53-63 $\mu \mathrm{m}, 90-125 \mu \mathrm{m}, 150-180 \mu \mathrm{m}$ and $300-355 \mu \mathrm{m}$. All substrates were prepared for use by rinsing several times in phosphate-buffered saline, followed by autoclaving and resuspension in culture medium. Figure 1 compares the surface area and number of microcarriers per gram of bead for each group. For most experiments, we used $40 \mathrm{mg}$ of the microcarriers, providing a surface area of approximately 41 sq. cm per culture for the 53-63 $\mu \mathrm{m}$ microcarriers, 22 sq. $\mathrm{cm}$ for the $90-125 \mu \mathrm{m}$ beads, $14 \mathrm{sq}$. $\mathrm{cm}$ for the $150-180 \mu \mathrm{m}$ beads and 7 sq. $\mathrm{cm}$ for the $300-355 \mu \mathrm{m}$ beads. In certain experiments, the large beads were also used at $160 \mathrm{mg} / \mathrm{dish}$, providing a surface area of 29 sq. $\mathrm{cm}$ per culture. This is in comparison to $9.6 \mathrm{sq}$. $\mathrm{cm}$ of surface area in a $35-\mathrm{mm}$ (diameter) culture dish.

Assessment of cell attachment, cell growth and microcarrier aggregation. Microcarriers were added in a 2-ml volume of culture medium to $35 \mathrm{~mm}$ (diameter) plastic petri dishes that had been coated overnight with $1 \%$ bovine serum albumin (BSA). BSA-coating was done to retard cell attachment to the culture dish. The culture medium was equilibrated by incubation for 1 hour at $37{ }^{\circ} \mathrm{C}$ in $5 \% \mathrm{CO}_{2} / 95 \%$ air. Fibroblasts that had been harvested from a monolayer culture were added to the dishes in the desired amount. Cells and microcarriers were mixed by gentle swirling of the dishes at 15 minute intervals over a 2 -hour period. Cell attachment was assessed at the desired times by aspirating the contents of the dishes into tubes and allowing the microcarriers with attached cells to settle. The non-attached cells were discarded, following which the attached cells were separated from the substrate by exposure to trypsin/EDTA and counted with a hemacytometer. This provided a direct cell count. In addition, a fraction of each sample was centrifuged to remove the proteolytic enzyme, resuspended in growth medium and plated in plastic culture flasks. Four hours later, the number of cells that had reattached and spread was determined microscopically. This was used to provide an indication of cell viability. In parallel dishes, microcarrier aggregation was assessed by counting the number of microcarriers present as single beads, the number in small aggregates ( $<20$ beads/aggregate) and the number in large aggregates (everything else) under phase-contrast microscopy.

In addition to the experiments in small-scale culture, 100-ml suspension culture experiments were also carried out. Cells and microcarriers were kept in suspension by continuous stirring. In other ways, the 100$\mathrm{ml}$ suspension cultures were handled in the same manner as the small-scale (2-ml) cultures.

\section{Results and discussion}

Fibroblast attachment to microcarriers of varying size: relationship between cell attachment and microcarrier aggregation. In the first series of experiments, dermal fibroblast attachment to the polystyrene microcarriers was assessed. Microcarrier aggregation was determined in parallel. As indicated in the upper panel of Figure 1, fibroblasts rapidly attached to the smallest (53-63 $\mu \mathrm{m})$ polystyrene microcarriers. Attachment was slower on the two intermediate-sized microcarriers and slowest on the large beads (300-355 $\mu \mathrm{m})$. As seen in the lower panel, there was a relationship between cell attachment and microcarrier aggregation. That is, aggregate formation occurred earlier and more extensively with the small-microcarriers, where cell attachment was also more rapid. In additional studies, the small (53-63 $\mu \mathrm{m})$ microcarriers were used at 

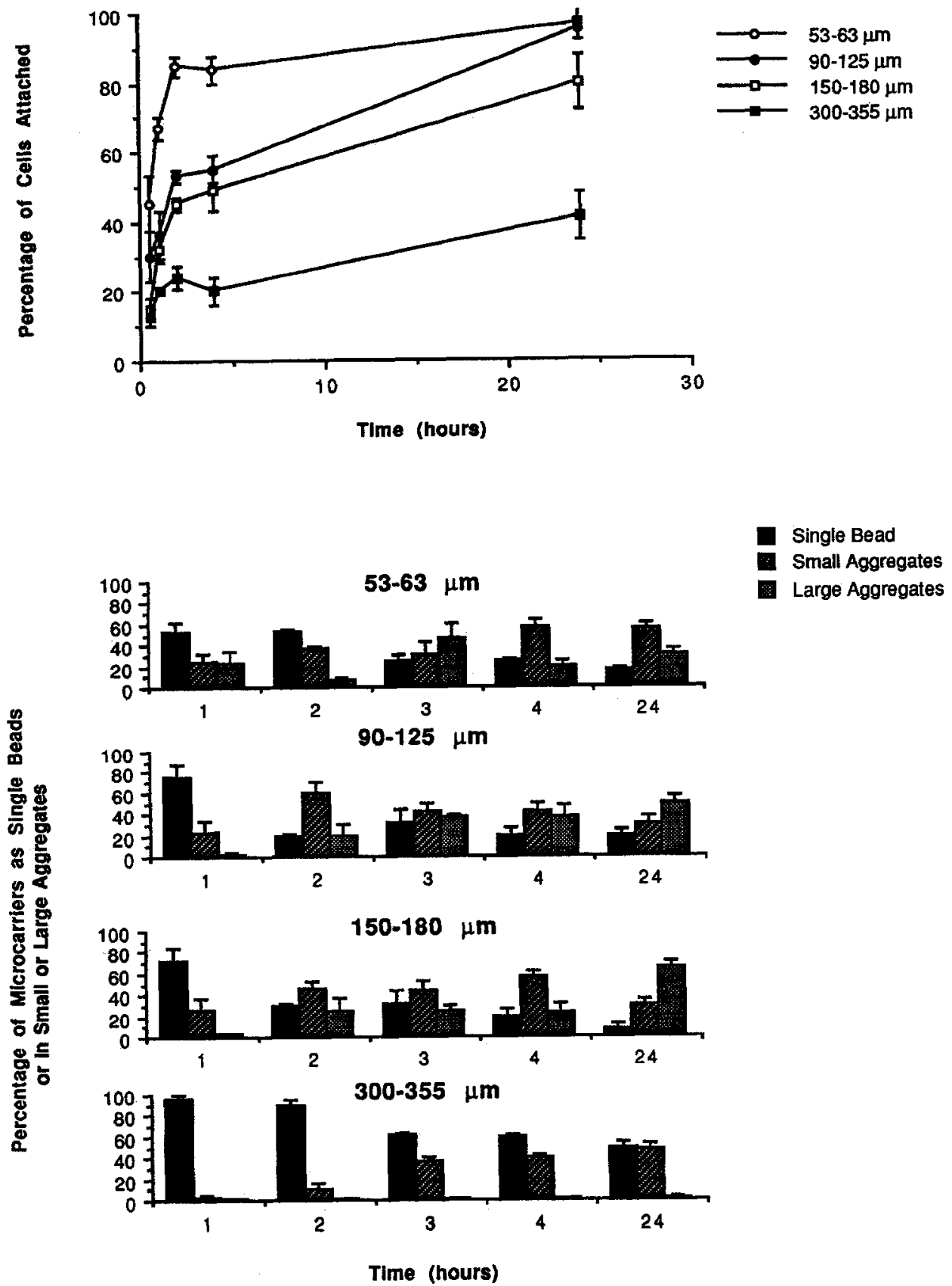

Figure 1. Upper panel: Attachment of human diploid fibroblasts to polystyrene microcarriers of various sizes as a function of time. Lower panel: Aggregation of different-size microcarriers as a function of time. The values shown represent averages \pm standard errors of the means, based on quadruplicate experiments with duplicate samples per data-point. 


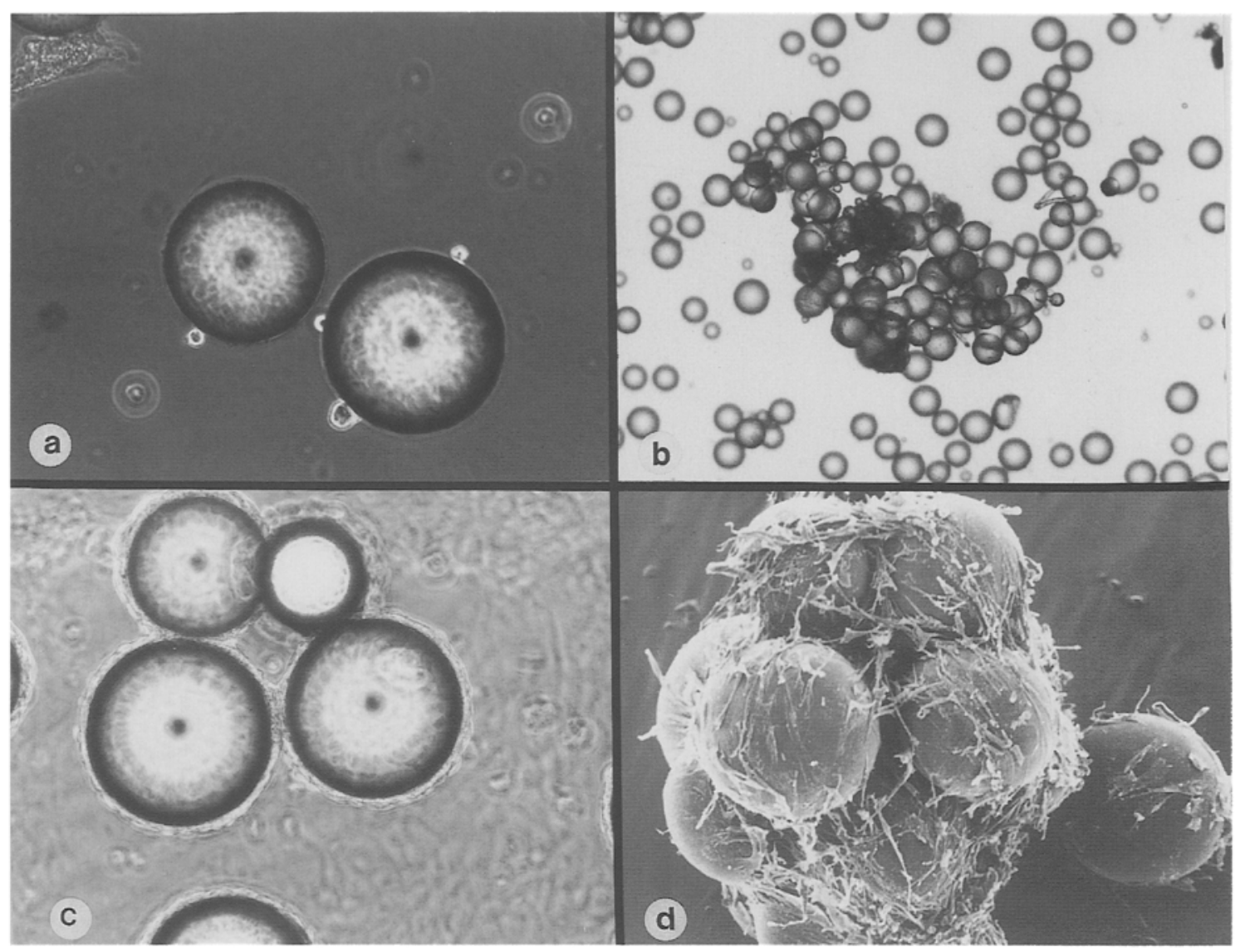

Figure 2. Light, phase-contrast and scanning electron microscopic evaluation of cells in microcarrier aggregates. Panel A is a phase-contrast micrograph showing single microcarriers immediately after addition of cells. A few cells have attached but have not yet spread. Panel B shows a light microscopic view of the small microcarriers four hours after inoculation of cells. Extensive aggregation has occurred. Panel $\mathrm{C}$ shows by phase-contrast microscopy that the aggregated microcarriers are heavily laden with cells. Panel $\mathrm{D}$ is a scanning electron micrograph showing the interstices of an aggregate. In spite of extensive cell growth, the majority of the space within the aggregate appears to be void volume.

$20 \mathrm{mg} /$ dish and the large (300-355 $\mu \mathrm{m})$ microcarriers were used at $160 \mathrm{mg} / \mathrm{dish}$. Even under these conditions, the differences in cell attachment and microcarrier aggregation were still evident (data not shown). Figure 2 shows a series of light, phase-contrast and scanning electron microscopic images of fibroblasts in microcarrier aggregates. While it can be seen that aggregate formation is extensive, panel $D$ shows that most of the aggregate is, in fact, void volume. Thus, it would not be unreasonable to suggest that nutrients, synthesized biologicals and waste products would be able to freely diffuse in and out of the aggregates.

Using the smallest microcarriers $(53-63 \mu \mathrm{m})$ at $40 \mathrm{mg} / \mathrm{dish}$, we next assessed the effects of varying the cell number on microcarrier aggregation. When the inoculum was reduced from $1 \times 10^{5}$ to $2.5 \times 10^{5}$ cells per dish, aggregation was retarded. When the inoculum was increased to as high as $5 \times 10^{6}$ cells per dish, aggregate formation was increased (Figure 3 ).

Taken together, these studies show that diploid fibroblasts rapidly attach to the polystyrene microcarriers and induce the microcarriers to aggregate. It is evident from this study that the smallest microcarriers (53-63 $\mu \mathrm{m}$ in diameter) support aggregation. In fact, it appears that the smallest microcarriers support cell attachment and aggregation more efficiently that microcarriers of larger size. There are a number of possible reasons for this. With the large beads, cells attached and spread fully on individual beads, thus limiting their interaction with multiple microcarriers. Furthermore, it is likely that the massiveness of the large beads prevents cells from generating the forces 


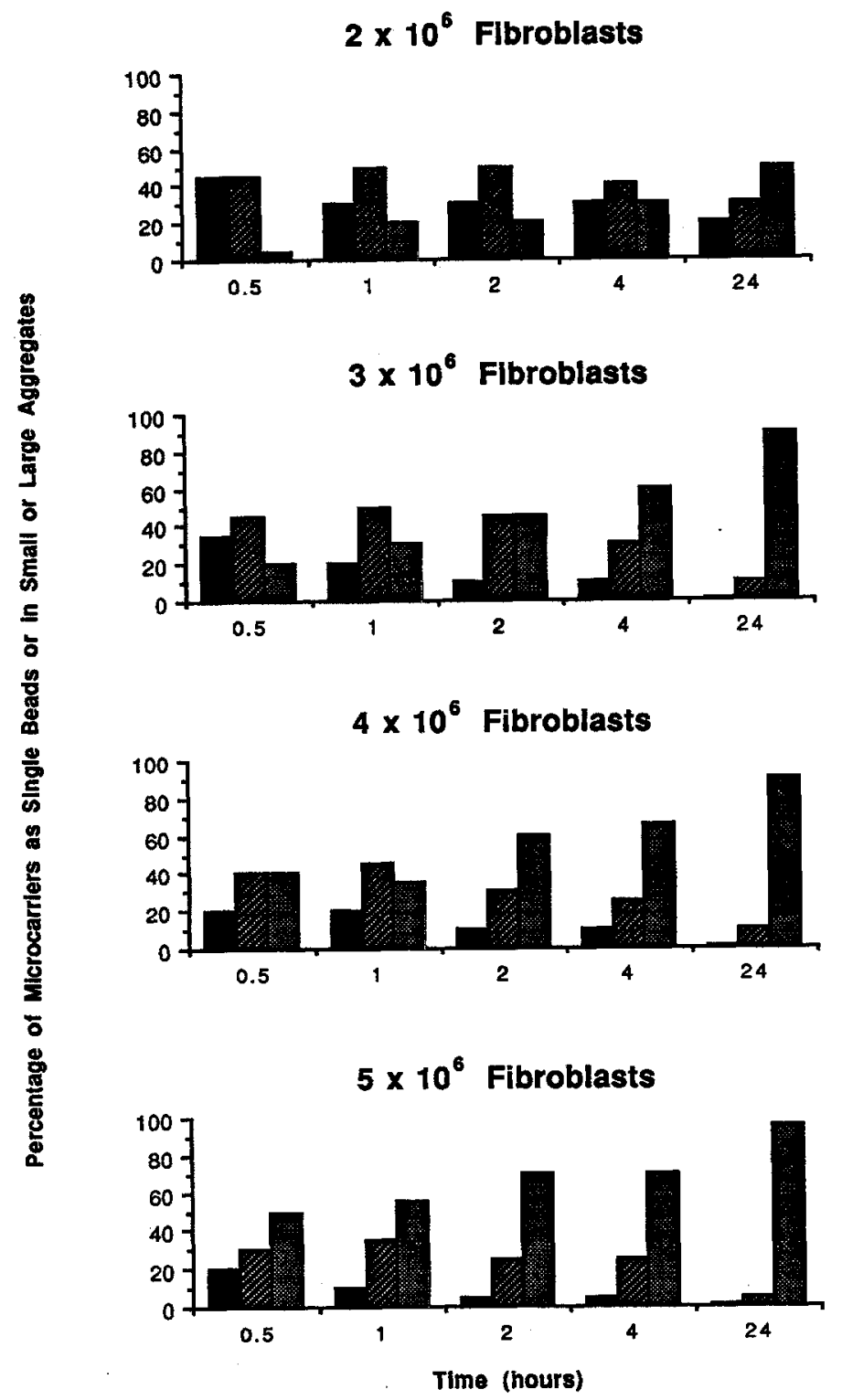

Figure 3. Aggregation of small $(53-63 \mu \mathrm{m})$ microcarriers as a function of cell inoculum. The values shown represent averages based on duplicate samples per time-point. Values for the duplicate samples were within $10 \%$ of the mean values. The experiment was repeated three times with similar results.

necessary to hold the beads together while the aggregates are forming. Another possibility is differences in surface charge density or concentration. Since volume decreases more rapidly than surface area as sphere size is reduced, the surface charge (responsible for initial interaction with the cells) may be greater in the small microcarriers than in the larger beads. Finally, differ- ences in attachment may be related to differences in surface area per se. On a per weight basis, the surface area of the small microcarriers is much greater than of the larger microcarriers. However, we do not believe that the difference in surface area is the major cause of the variation in attachment kinetics or microcarrier aggregation. When surface area differences were elim- 

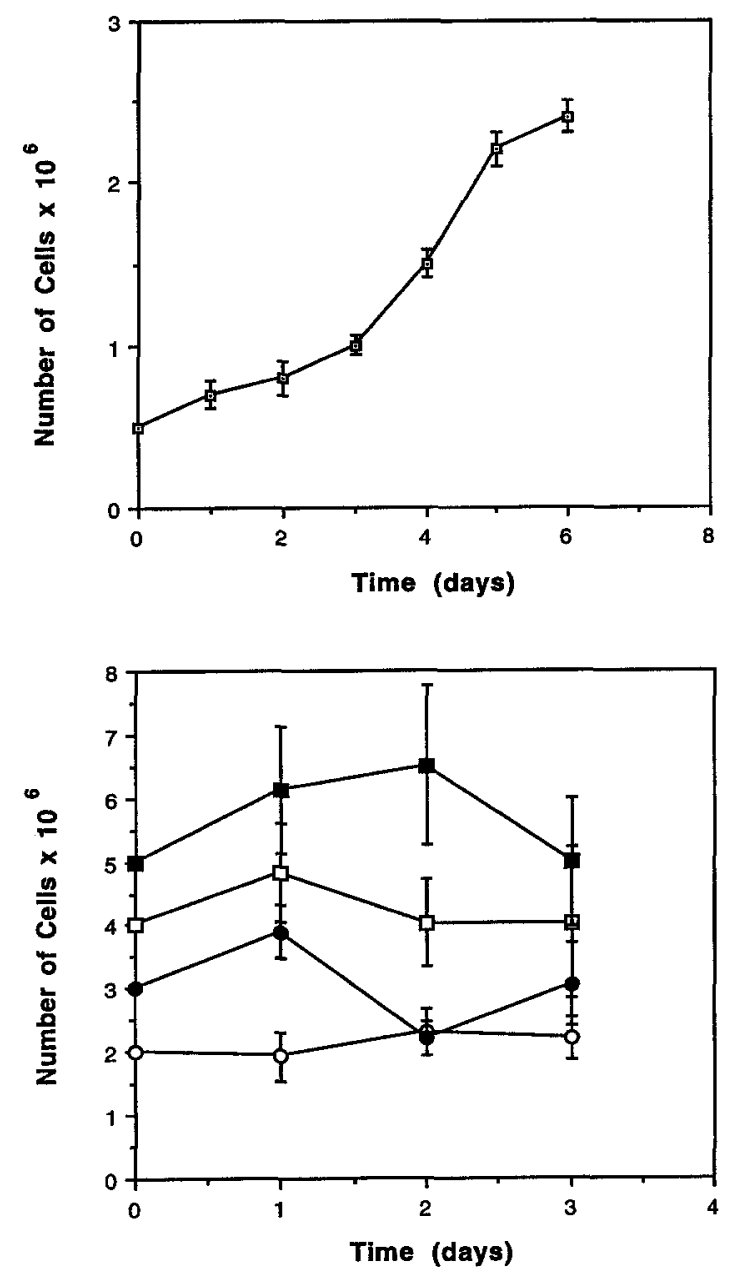

Figure 4. Upper panel: Growth of human diploid fibroblasts on small (53-63 $\mu \mathrm{m}$ ) microcarriers. Lower panel: Maintenance of fibroblasts at high density in microcarrier aggregates. Values shown are averages \pm differences between individual values and averages, based on duplicate samples in a single experiment. The experiment was repeated three times with similar results.

inated (by decreasing the small-microcarrier concentration by a factor of two and increasing the concentration of large-microcarriers by four-times), differences were still observed. In any event, the real question is not whether and how aggregation can be induced but, rather, the effects of aggregation on cell viability and growth. To address this issue, growth studies were conducted using the small-microcarriers.

Fibroblast growth in microcarrier aggregates. Figure 4 (upper panel) shows results of studies in which $5 \times 10^{5}$ cells were used as the inoculum in 2-ml cultures con- taining $40 \mathrm{mg}$ of the small $(53-63 \mu \mathrm{m})$ microcarriers. Extensive growth occurred such that by day 6 there were over $2.5 \times 10^{6}$ cells per culture as indicated by direct count. When cells were harvested from the microcarrier cultures and replated, virtually all of the cells $(>95 \%)$ were able to reattach and spread. Thus, not only was there extensive growth on the microcarrier aggregates, but a high level of cell viability was also maintained. In parallel studies, virtually identical results were obtained with cells in monolayer culture (not shown).

Cells were next added to the small microcarriers at concentrations ranging from $2-5 \times 10^{6}$ cells per dish ( $40 \mathrm{mg}$ of microcarriers in $2 \mathrm{ml}$ ). The cultures were incubated over a 3-day period with fresh culture medium provided daily. Although there was little net growth at these densities, virtually all of the cells added to the microcarriers survived incubation under these conditions (Figure 4, lower panel). In contrast, when the cells were added at high density $\left(5 \times 10^{6}\right.$ cells per dish) to $35 \mathrm{~mm}$ (diameter) plastic culture dishes containing 2-ml of culture medium, the cells initially attached. However, the available substrate in the dishes (approximately $9.6 \mathrm{~cm}^{2}$ ) was not sufficient to maintain that level of cells, and within 24 hours the cells detached from the substratum and died (not shown).

In a final set of studies, fibroblasts were grown in 100-ml suspension culture using the small (53-63 $\mu \mathrm{m}$ ) microcarriers at $20 \mathrm{mg} / \mathrm{ml}$ as substrate. Cells were seeded at $1 \times 10^{5}$ cells per $\mathrm{ml}$ and incubated over a 7 -day period with fresh culture medium provided at 2-day intervals. Under these conditions results very similar to those seen in the small-scale experiments were seen. That is, there was rapid cell attachment, extensive aggregation and good cell growth. Specifically, $90 \%$ of the initially added cells were attached after one day and approximately $70 \%$ of the microcarriers were in large aggregates by this time. By day seven, cell numbers had increased from $1 \times 10^{5}$ per $\mathrm{ml}$ to greater than $7 \times 10^{5}$ per ml. Thus, human diploid fibroblast grew well on small-microcarrier aggregates in both small-scale and 100-ml cultures.

\section{Conclusions}

Based on this study we conclude the following: (1) that formation of microcarrier aggregates does not $a$ priori inhibit fibroblast growth; and (2) that small (53$63 \mu \mathrm{m})$ microcarriers are very efficient is supporting fibroblast attachment and cell growth. 
Table 1. Physical characteristics of the polystyrene microcarriers

\begin{tabular}{cll}
\hline $\begin{array}{l}\text { Size distribution } \\
\text { (diameter range) }\end{array}$ & $\begin{array}{l}\text { Number of microcarriers } \\
\text { per gram }\left(\times 10^{6}\right)\end{array}$ & $\begin{array}{l}\text { Surface area } \\
\text { (sq. cm. per gram) }\end{array}$ \\
\hline $53-63 \mu \mathrm{m}$ & 10 & 1014 \\
$90-125 \mu \mathrm{m}$ & 2 & 547 \\
$150-180 \mu \mathrm{m}$ & 0.42 & 357 \\
$300-355 \mu \mathrm{m}$ & 0.05 & 180 \\
\hline
\end{tabular}

With regard to cell growth in aggregates, it is possible that formation of 3-dimensional aggregates allows the cells to more effectively utilize paracrine loops, where growth factors secreted by one cell are used by neighboring cells. Perhaps in the same manner, the formation of 3-dimensional aggregates will allow for a more efficient cell-to-cell transfer of viruses in the vaccine manufacture process. With regard to the successful cultivation of diploid fibroblasts on the small beads, this argues against the view that microcarriers below approximately $75 \mu \mathrm{m}$ could not be used as substrate. It had been thought that cells would be unable to conform to the geometry of the small-bead surface and that this would inhibit growth (Nielson \& Johannson, 1980 ). Evidently, human diploid fibroblasts are capable of obviating this requirement by spanning multiple beads.

\section{Acknowledgement}

This study was supported in part by NIH grant CA1616 from the USPHS.

\section{References}

Alves PM, Moreina JL and Carrondo MJT (1994) BHK in suspended batch culture: Growth as natural aggregates and in porous and non-porous microcarriers. Abstracts of the 207th Meeting of the American Chemical Society (Division of Biotechnology). San Diego, CA.

Goetghebeur S and $\mathrm{Hu}$ WS (1991) Cultivation of anchoragedependent cells in microsphere-induced aggregate culture. Appl Microbiol Biotech 34: 735-741.

Lewis D, Phillips J, Ram K and Seifert D (1994) Characterization of microcarrier aggregates. Abstracts of the IV Cell Culture Engineering Conference. San Diego, CA.

Nielson V and Johannson A (1980) Biosilon: Optimal culture conditions and various research scale culture techniques. Develop Biol Stand 46: 131-136.

Phan SH, Varani and Smith D (1985) Rat lung fibroblast collagen metabolism in bleomycin-induced pulmonary fibrosis. J Clin Invest 76: 214-247.

Van Wezel AL (1967) Growth of cell strains and primary cells on microcarriers. Nature 216: 65-66.

Address for correspondence: James Varani, Ph.D., Department of Pathology, The University of Michigan, 1301 Catherine Rd/Box 0602, Ann Arbor, MI 48109, USA. 